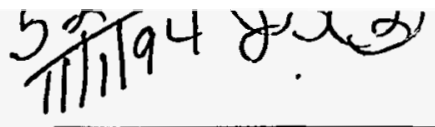

PREPARED FOR THE U.S. DEPARTMENT OF ENERGY, UNDER CONTRACT DE-AC02-76-CHO-3073

- PPPL-3010

UC-420,426

\title{
D-T RADIATION EFFECTS ON TFTR DIAGNOSTICS
}

BY

A.T. RAMSEY

OCTOBER 1994

\section{$\int D \int D \int\left[\begin{array}{l}\text { PAINCETON } \\ \text { PLASMA PHYSIES } \\ \text { LABORATORY }\end{array}\right.$}

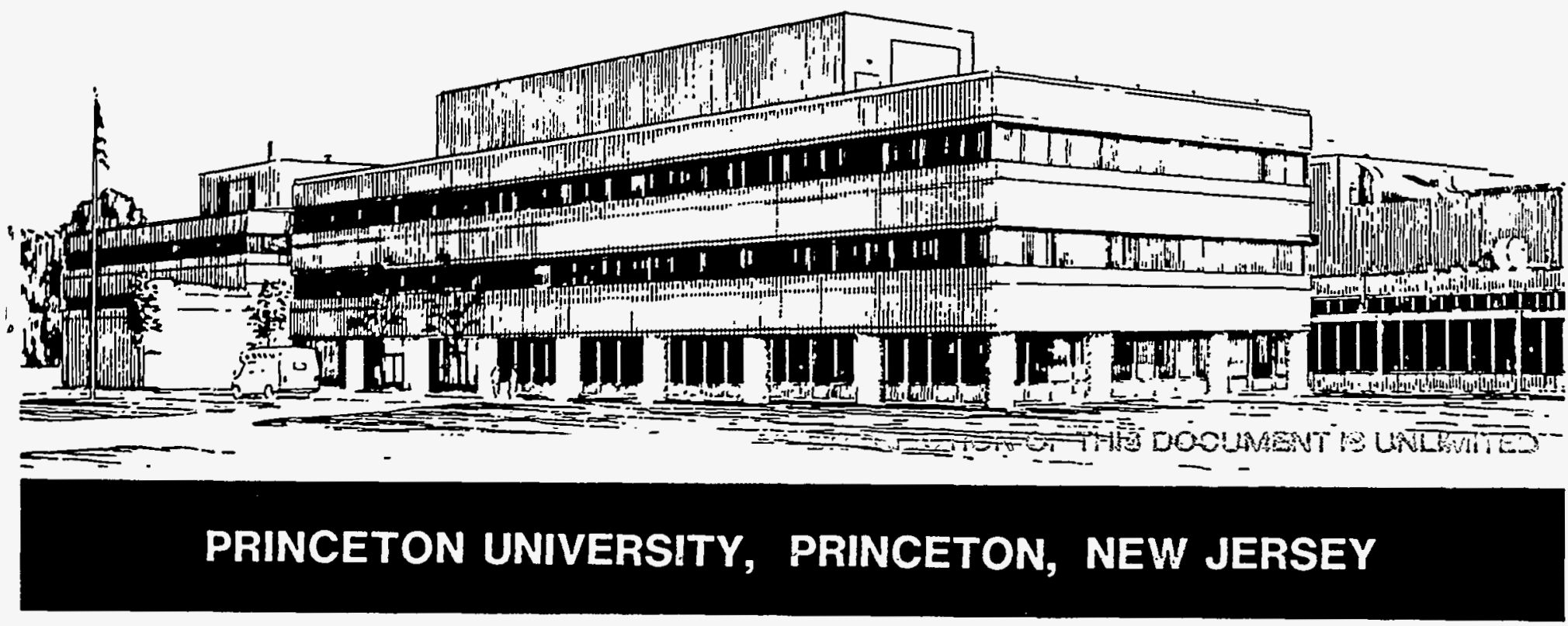


NOTICE

This report was prepared as an account of work sponsored by an agency of the United States Government. Neither the United States Government nor any agency thereof, nor any of their employees, makes any warranty, express or implied, or assumes any legal liability or responsibility for the accuracy, completeness, or usefulness of any information, apparatus, product, or process disclosed, or represents that its use would not infringe privately owned rights. Reference herein to any specific commercial produce, process, or service by trade name, trademark, manufacturer, or otherwise, does not necessarily constitute or imply its endorsement, recommendation, or favoring by the United States Government or any agency thereof. The views and opinions of authors expressed herein do not necessarily state or reflect those of the United States Government or any agency thereof.

\section{NOTICE}

This report has been reproduced from the best available copy.

Available in paper copy and microfiche.

Number of pages in this report: 18

DOE and DOE contractors can obtain copies of this report from:

Office of Scientific and Technical Information

P.O. Box 62

Oak Ridge, TN 37831 ;

(615) $576-8401$.

This report is publicly available from the:

National Technical Information Service

Department of Commerce

5285 Port Royal Road

Springfield, Virginia 22161

(703) $487-4650$ 


\section{DISCLAIMER}

Portions of this document may be illegible in electronic image products. Images are produced from the best available original document. 


\title{
D-T radiation effects on TFTR diagnostics ${ }^{\dagger}$
}

\author{
A. T. Ramsey \\ Plasma Physics Laboratory, \\ Princeton University \\ Post Office Box 451 \\ Princeton, New Jersey 08543
}

\section{Abstract}

For a $50 \%-50 \%$ deuterium-tritium plasma, the neutron production is $80 \times$ higher and the total energy release is $200 \times$ higher than the same plasma composed only of deuterium. With this increase in radiation, diagnostics which see only negligible amounts of noise during DD operation may find themselves overwhelmed during DT. The neutrons are not only more numerous, but have $6 \times$ as much energy, which causes the calculated $2.4 \times$ increase in the gamma flux per neutron near TFTR.

We report here the effects of this increased radiation on the TFTR diagnostic set. The most noticeable effects are luminescence and transmission losses in fiber optic signal cables. In addition, a plastic fiber near the torus became unusably opaque after a few DT discharges. Silicon detectors show signs of neutron interactions as well as gamma response, and microchannel electron multipliers show an increased background due to the gamma flux. Bolometers show $\mathrm{n}$ and $\gamma$ heating, and the Thomson scattering intensifier gate spark gap was unreliable until the gas pressure was adjusted. Sensitive solid state components failed.

All of these effects were anticipated, and in some cases shielding or compensation techniques were used. Compensation fibers work satisfactorily at these radiation levels, and the rapid fall-off of the radiation as one moves away from the machine makes relocation of fibers and other sensitive components very useful. Conventional shielding designs worked when streaming through signal penetrations was properly dealt with.

In coming DT campaigns and the generation of new tokamaks, such problems will be more severe. JET anticipates higher dose levels per shot during DT; TPX has $1000 \mathrm{~s}$ pulses (although in DD), and ITER presents a particularly difficult challenge. We shall discuss the implications of our results for diagnostics on these machines.

$\mp$ This is an expanded version of a paper with the same title accepted for publication in the Review of Scientific Instruments in connection with the $10^{\text {th }}$ Conference on High Temperature Plasma Diagnostics, held in Rochester, New York. May 8 through May 12, 1994.

$$
\text { MASTER }^{\text {Non }}
$$




\section{Introduction}

Princeton University's Tokamak Fusion Test Reactor (TFTR) is the first tokamak to regularly use tritium mixed with deuterium as a fuel. Tritium greatly increases the fusion reaction rate of the confined plasma, and the reaction products are more energetic than those of deuterium alone. On TFTR, for example, the fusion energy released has increased by a factor of more than 200 over comparable deuterium only plasmas.

With this greatly increased fusion energy output comes a greatly increased challenge to the diagnostic set. Noise, spurious signals, and component damage all increase in proportion to the energy production. It is useful at this time, therefore, to see how the TFTR diagnostics have met the challenge, and what the results may indicate for the future. The European Community's Joint European Torus begins a campaign in tritium in 1996, Princeton University's long pulse Tokamak Physics Experiment (TPX) is approaching a final design stage, and the $1000 \mathrm{MW}$ International Tokamak Experimental Reactor (ITER) looms on the horizon.

I shall begin this review with a brief discussion of the increased radiation levels from a deuterium-tritium (DT) mixture compared to plasmas fueled with deuterium alone (DD). In Section III, I shall describe the transient effects of radiation on diagnostics (effects such as noise and spurious signals), and show that the magnitudes are close to those expected. In Section IV the permanent radiation effects (fiber transmission loss, component failure) are presented. I shall then describe our remediation efforts in Section V, and show how they succeeded. Finally we shall look to the future, and try in Section VI to predict what this present experience means for the next generation of experiments.

\section{Radiation characteristics and effects}

At an ion temperature of $T_{i}=20 \mathrm{keV}$, the DT reaction rate, $\left\langle\sigma v_{i}\right\rangle$, is 80 times higher than DD. ${ }^{1}$

1

$$
\frac{\langle\sigma \mathrm{v}\rangle_{\mathrm{DT}}}{\langle\sigma \mathrm{v}\rangle_{\mathrm{DD}}}=\frac{4.2 \times 10^{-16} \mathrm{~cm}^{3} \mathrm{~s}^{-1}}{5.2 \times 10^{-18} \mathrm{~cm}^{3} \mathrm{~s}^{-1}} \approx 80
$$

Also, the energy released per fusion event is 5 times higher:

$$
\begin{array}{ll}
2 \mathrm{a} & \mathrm{D}+\mathrm{D}\left\langle{ }^{3} \mathrm{He}(0.8 \mathrm{MeV})+\mathrm{n}(2.45 \mathrm{MeV})\right. \\
\mathrm{T}(1.0 \mathrm{MeV})+\mathrm{p}(3.0 \mathrm{MeV}) & \langle\Delta \mathrm{E}\rangle=3.6 \mathrm{MeV} \\
2 \mathrm{~b} & \mathrm{D}+\mathrm{T}-{ }^{4} \mathrm{He}(3.5 \mathrm{MeV})+\mathrm{n}(14.0 \mathrm{MeV}) \Delta \mathrm{E}=17.5 \mathrm{MeV}
\end{array}
$$

(At these temperatures the two $\mathrm{D}+\mathrm{D}$ reaction channels are equally probable.) 
We have measured the neutron fluences around TFTR using neutron activation techniques. ${ }^{2}$ For a DT plasma producing $1 \times 10^{18}$ neutrons (corresponding to $2.8 \mathrm{MW}$ of total fusion power), the areas near vacuum vessel port covers receive a neutron flux of about $2 \times 10^{12} \mathrm{n}-\mathrm{cm}^{-2}-\mathrm{s}^{-1}$. If we use these results to benchmark the neutron transport and radiation prediction calculations, ${ }^{3}$ we can infer a radiation dose of about $5 \mathrm{~Gy}-\mathrm{s}^{-1}$ for this neutron production rate. The neutron spectrum outside the vacuum vessel is calculated to be nearly identical for DD and DT except for the region above the birth energy of the DD neutrons, $2.45 \mathrm{MeV}$. The external gamma spectrum has about the same shape in DT as it does in DD, but is predicted to be 2.4 times more intense in DT near the vacuum vessel.

The neutrons themselves can cause radiation effects. A neutron knock-on event in the sensitive region of a silicon detector causes a huge spike from the intense ionization track. Also, DT neutrons can cause reactions such as ${ }_{14}^{28} \mathrm{Si}(\mathrm{n}$,p), whose $4 \mathrm{MeV}$ threshold is above the birth energy of the DD neutrons. Finally, neutrons can produce noticeable effects through atomic dislocations in structure sensitive materials such as intrinsic or lightly doped semiconductors.

Most of the radiation effects, however, are caused by gammas. Gammas arise from inelastic scattering of neutrons and from $(n, \gamma)$ capture reactions following the rapid thermalization of the neutrons. The gamma spectrum extends up to about $10 \mathrm{MeV}$. These gammas cause ionization and excitation in detectors, either directly or by Compton- and photoelectric-accelerated electrons.

\section{Transient radiation effects}

In this section we shall examine the effects which occur during the neutron producing phase of the shot. These effects interfere with the signals, but do not necessarily damage the diagnostic instruments themselves.

Direct heating of very sensitive components exposed to high fusion flux levels is already seen in TFTR. The TFTR bolometer system ${ }^{4}$ shows falsely high readings during DT. Ionization (or photo-electric emission) causes noise in microchannel plate electron multipliers (MCP's). This noise raises the background level of signals, and adds noise to them. As I shall show below, it also reduced the dynamic range of an MCP detector to the point of uselessness. Ionization increases the noise levels in silicon junction based detector's, such as CCD's and $\mathrm{Si}(\mathrm{Li}) \mathrm{X}$-ray detectors. It is a serious noise source in proportional counters. On TFTR's X-ray Bragg spectrometer, ${ }^{5}$ shielding was installed that allowed successful operation during DD plasmas, but the gammas in DT overwhelm the pulse detection circuitry and all the data are lost. Finally, the spark gap 
for the Thomson scattering detector misfired due to gamma induced ionization even though it is located in the Test Cell basement. (A readjustment of the operating gas pressure restored the reliability.)

Direct interaction of neutrons (or gammas) in detectors can do more than cause noise. The electron well depth of a CCD is so shallow that a neutron knock-on event can saturate it, giving a totally "white" pixel. Our CCD cameras, both in the Test Cell where the tokamak is housed (TV cameras) and even in the well-shielded Hot Cell (spectrometer detectors), show saturated pixels; this is not serious for a TV camera, but required us to put heavy shielding around the CCD detector for the $\alpha$-CHERS system (even though this is an area safe for human occupation during plasmas). ${ }^{6}$

The construction of TFTR coincided with the rapid development of high throughput, inexpensive optical fibers, and they are ubiquitous around the machine. (JET, built several years later, has even more optical fibers.) There are two transient effects of radiation in fibers; luminescence (sometimes called radioluminescence), and transient opacity.

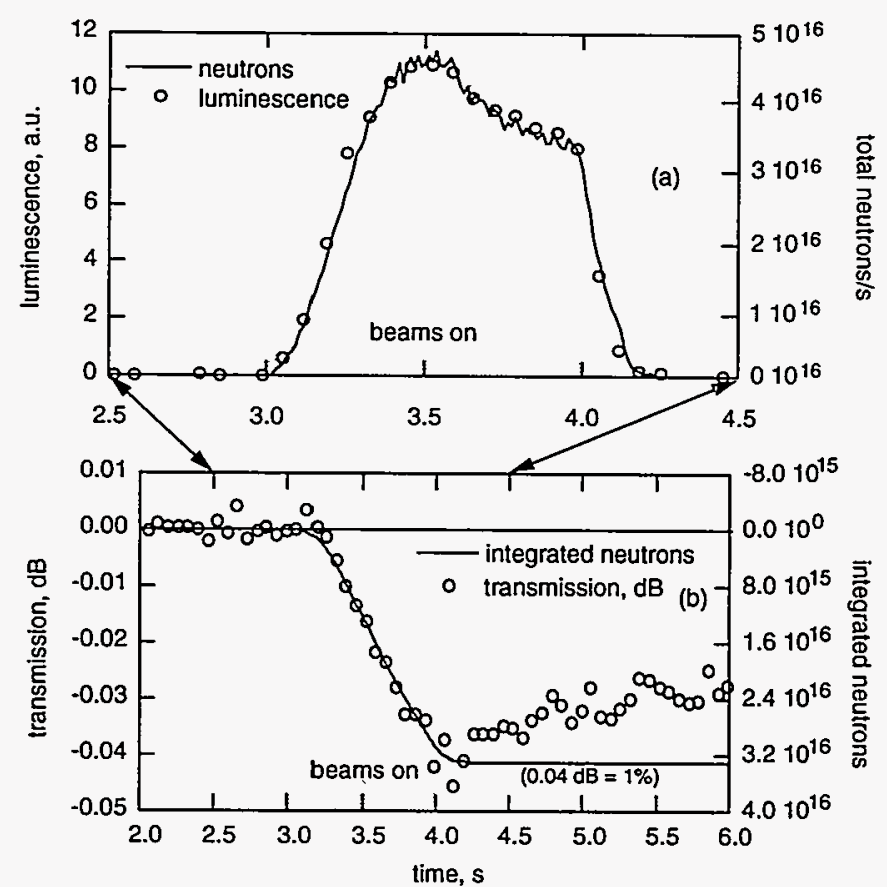

Figure 1. Radioluminescence and transmission loss in an optical fiber during a DD plasma discharge. Fig. la shows the luminescence (in arbitrary units) overlaid with the total neutron production rate. Fig. 1b shows the loss of transmission with the integrated neutron rate. As soon as the neutron production stops, the transmission starts to recover.
Figure 1 shows these effects. The luminescence is shown in Fig. 1a with the total neutron production rate (which has the same time dependence as the gamma production). The observed luminescence in a given fiber is linearly proportional to neutron rate up to the highest levels we have observed on TFTR, which is $2.2 \times 10^{18} \mathrm{~s}^{-1}$ (corresponding to a near-vessel neutron flux of $4.4 \times 10^{12} \mathrm{n}-\mathrm{cm}^{-2}-\mathrm{s}^{-1}$ and a radiation dose rate of $11 \mathrm{~Gy} \mathrm{~s}^{-1}$ ). The radioluminescence near the vessel on the midplane from DT neurons is measured to be 2.4 times as bright per neutron as in DD. This is just the predicted ratio of DT to DD gamma flux per neutron (see above). We note here that Morgan, measuring the same 
phenomenon on JET, sees no difference in the per neutron luminescence between DD and DT plasmas. ${ }^{7}$ It has been suggested that, because of the much heavier structure of JET, the neutron spectrum is so moderated by the time it emerges from the vacuum vessel and the surrounding structure that there is no difference in the subsequent gamma flux. The calibration results of the JET ${ }^{238} \mathrm{U}$ fission chamber neutron detectors in current mode are consistent with this. ${ }^{8}$.

Figure 1b shows the loss in transmission during the same shot compared with the integral of the neutron production: the damage accumulates during the shot. The change in opacity during a shot can be very serious: it falsely decreases the amplitude of continuum measurements such as the visible bremsstrahlung, and it distorts the line shape of a spectrometer if the transmission changes as the pixels under the line are being read out. Since the transmission decreases during the shot and starts to recover immediately, afterwards, pre- and post-shot calibrations are not useful. I have shown data in Fig. I for a DD shot where the transmission loss is low; otherwise, the transmission loss distorts the detected radioluminescence. For a modest DT shot, a typical diagnostic system suffers a loss of 5-7\%.9 The transmission loss in DT shots is measured to be 2.4 times greater per neutron than in DD, which argues that gamma radiation is responsible for the damage which causes it.

Even where the data are spectrally resolved, fiber luminescence causes problems. Figure 2 shows the effects of luminescence in a coherent fiber bundle of the Lost- $\alpha$ system. ${ }^{10}$ The signal from escaping $\alpha$-particles is clearly visible since it is resolved in both pitch angle and gyro radius. However, this alpha signal rides on top of a luminescent background that is comparable in size to the true signal, and noise is added

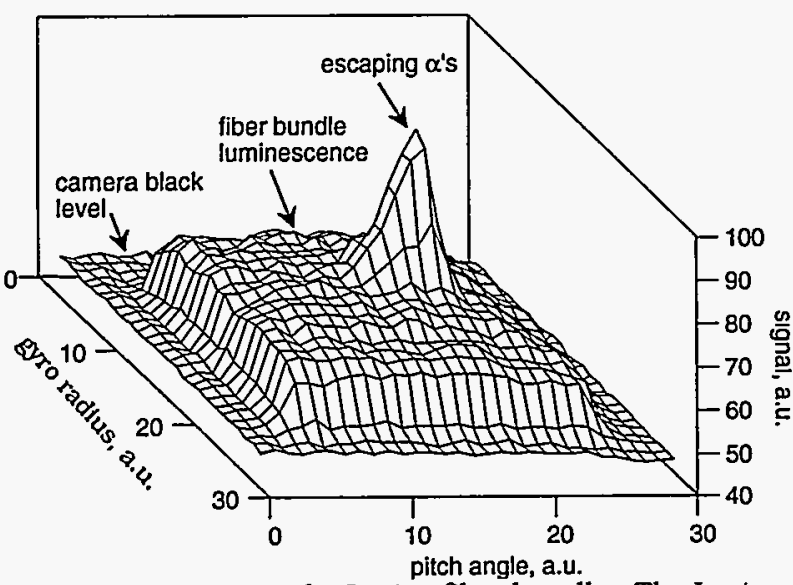

Figure 2. Luminescence in the Lost- $\alpha$ fiber bundle. The Lost- $\alpha$ signal is from a phosphor which peaks at $535 \mathrm{~nm}$, and is filtered with a $70 \mathrm{~nm}$ wide filter to eliminate most of the fiber luminescence. The fiber bundle was already shielded when these data were taken. to the signal. Even in this 6-frame average, we can clearly see noise on the background.

Both the radioluminescence and the transmission loss have strong spectral dependencies, and can vary by an order of magnitude between different high-purity silica fibers. In Figure 3, we see the spectrum of luminescence of a fiber used in the $\alpha$-CHERS system. ${ }^{6}$ The fiber is a $1 \mathrm{~mm}$ core polymer clad silica (PCS) fiber from Fiberguide Industries (Stirling, New Jersey). 


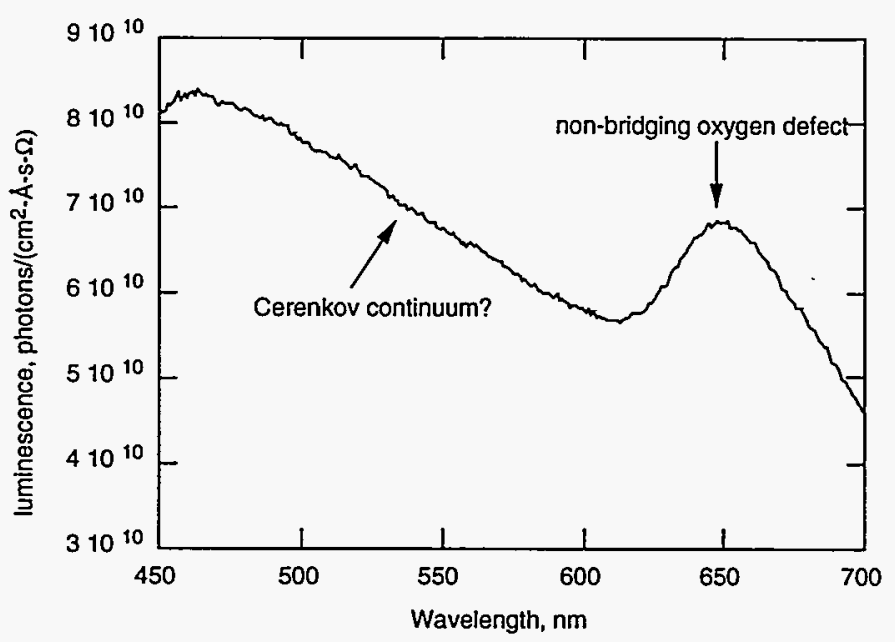

Figure 3. A radioluminescent spectrum from a PCS fiber, corrected for fiber transmission. The bump at $650 \mathrm{~nm}$ appears to be from non-bridging oxygen defects in the silica. The shape of the rest of the spectrum is consistent with Cerenkov radiation from electrons of $200 \mathrm{keV}$ or higher energy in the fiber core.
The spectrum is corrected for fiber transmission. The bump at 650 nm (which shows up as absorption in transmission) is the wellknown non-bridging oxygen defect in fused silica. ${ }^{11}$ The rest of the spectrum (except for the roll-off at $450 \mathrm{~nm}$, which we believe is an artifact of the calibration process) looks very much like a Cerenkov radiation spectrum. ${ }^{12}$ In silica, Compton electrons with more than $200 \mathrm{keV}$ energy emit Cerenkov radiation; electrons in this energy range can also penetrate the jacket and cladding of the fiber. The peak of the predicted TFTR Test Cell gamma spectrum is at several hundred $\mathrm{keV}$. We believe that Compton radiation contributes to

much of the TFTR radioluminescent spectrum. (The fact that luminescence per neutron in DT is greater by a factor of 2.4 , the same as the calculated gamma flux increase, is consistent with this.)

\section{Permanent effects of radiation}

Failure of diagnostic components has not been common on TFTR. Our total DT radiation dose near the machine after several months of DT operation is about $100 \mathrm{~Gy}$, which is just reaching the failure threshold of sensitive items. Also, we had made an effort not to leave sensitive unshielded components in the Test Cell. Nevertheless, we have observed some failures at these rather low accumulated doses.

All the opto-isolators used in the Thomson scattering laser beam alignment system failed; a post-mortem showed that the phototransistor current gain had fallen to $3 \%$ of its original value. Photodiodes are much hardier, but several of those have failed, too. Solid state motor controllers for the ICRF antenna system, which were located very close to the vacuum vessel, have also failed. A plastic optical fiber, used to supply timing information in a pellet injector, became unusably dark after 3 full DT shots. And the TV cameras, mounted at the Test Cell wall where the dose is only 1/30 of a near- 
machine location, are showing scattered dead pixels in their CCD detectors.

A more serious problem is the permanent loss in optical fiber transmission, since it builds up over time. While the data are still incomplete, we are starting to get a picture of this effect. (For a more complete discussion, see Adler et al. ${ }^{13}$ ) During neutron production the transmission falls. Absorption in optical fibers is from scattering by point defects or by excitation of electrons in color centers; the defects and the color centers can be created by the radiation, or ionization can furnish an electron to be trapped by an already existing vacant color center. Some of these defects start to anneal as soon as they are created. This is a complex process with multiple time constants. On the time scale of TFTR plasmas, our fibers have components at $0.24 \mathrm{~s}, 3.3 \mathrm{~s}$, and $46 \mathrm{~s}$, all with comparable creation coefficients. (See Section VI B.) There are longer time constants, too, but after several days the changes in transmission are small, and not all of the opacity has annealed out.

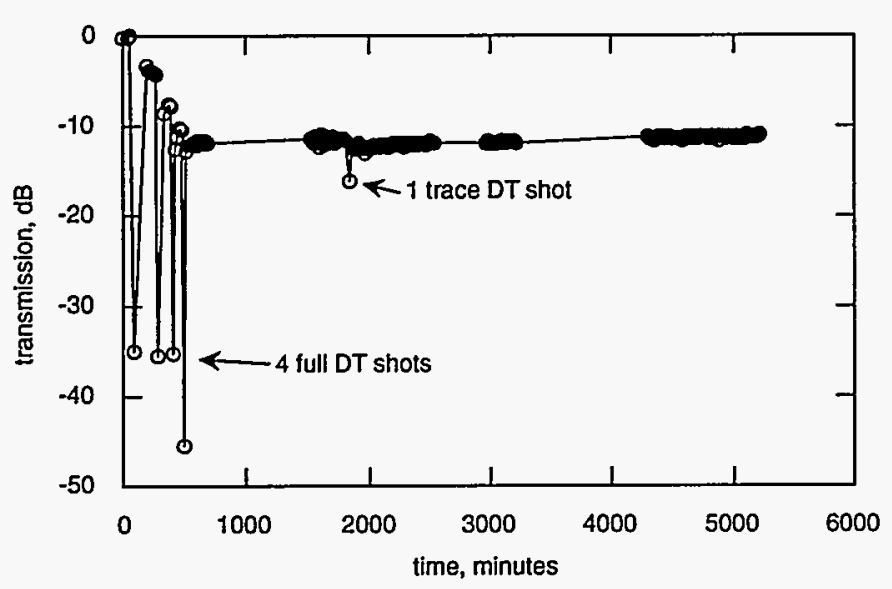

Figure 4. This is the transmission loss history of a $53 \mathrm{~m}$ coil of $600 \mu$ core PCS fiber near the TFTR vacuum vessel. The four large drops are full DT shots; the smaller drop at 1800 minutes was a trace tritium shot.
In Figure 4, we see the long term effect of full DT shots on a fiber. For this PCS fiber (the kind we commonly use), we find that, of the total after shot loss, nearly $8 \%$ remained after 24 hours. For a silica-silica fiber from the same manufacturer, only $3 \%$ remained, but that was $3 \%$ of a 6 times larger initial loss. Quantitatively, we saw a short term loss of $1.8 \times 10^{-13}$ (dB$\mathrm{m}^{-1}$ )/(neutrons- $\mathrm{cm}^{-2}$ ) for a $600 \mu$ core PCS fiber, and $11.7 \times 10^{-13}$ for the same size silica-silica fiber from the same manufacturer (Fiberguide). The long term losses $w$ $1.4 \times 10^{-14}$ and $3.4 \times 10^{-14}$ for PCS and silica-silica, respectively. Although these long term losses are not great, in an intensive run they will build up, and can cause serious calibration problems. We are still studying this effect.

\section{Remediation of radiation effects}

The radiation effects described above can have a serious impact on the proper operation of tokamak diagnostics. There are several ways to deal with the problem: planning, replacement, relocation, compensation, shielding, abandonment, and 
finally (for fibers) heating. I shall describe in this section which approach we took for various TFTR diagnostics.

\section{A. Planning}

TFTR was designed to be a DT machine, and diagnostics were located (when possible) away from the Test Cell in shielded areas. A change in our plans affected this, however. Initial location of diagnostics was done with the assumption that a $60 \mathrm{~cm}$ thick concrete igloo would cover the tokamak during DT operation. When budgetary cuts forced us to drop the igloo, more systems were put at risk.

\section{B. Replacement}

Thomson scattering needs opto-isolators in its Test Cell beam steering system. Radiation hardened units would cost thousands of dollars, and shielding would have been expensive and bulky. Opto-isolators cost less than $\$ 1$ each, and are plug-mounted. We decided to replace them when they fail or during maintenance periods. The TV cameras in the Test Cell also will be replaced when their CCD detectors lose so many pixels that the picture is judged poor.

\section{Relocation}

The radiation field falls off rapidly as one moves away from the tokamak itself. Figure 5 shows fiber luminescence taken with one of our movable fiber optic study loops, a $53 \mathrm{~m}$ coil of fiber on leads in the Test Cell, with the leads running to a remote shielded area. The setup of the study loops is the same as described below for the compensation loop, except that, in the study loop, the coil at the Test Cell end gives a very long length of fiber in a well defined location, so that greatly localized and

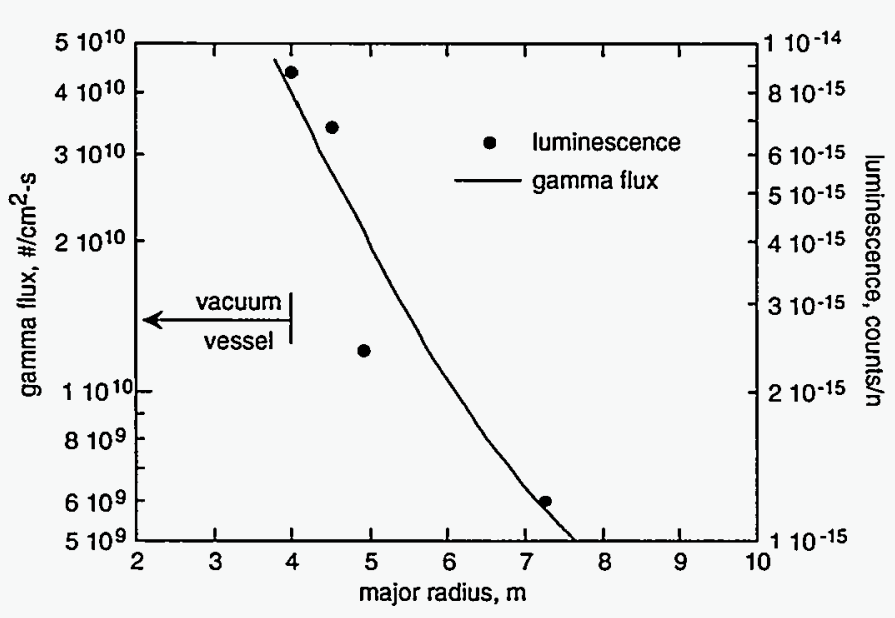

Figure 5. The dependence of radioluminescence on distance from the center of TFTR. The luminescence, normalized to the total neutron rate for inter-shot comparison, is compared with the calculated gamma flux on the midplane of TFTR for shots similar to those used in the luminescent measurements. amplified (by the length of the coil) spatial information on radiation effects can be gathered. Superimposed on these luminescence data in the figure is a calculated curve of the spatial dependence of the gamma flux on the tokamak midplane. The data support two claims: 1) the calculated spatial dependence of the radiation is rather accurate, despite enormous anisotropies in the Test Cell mass distribution, and 2) there is great advantage to be gained by getting even a little 
way back from the machine.

When we relocated the TFTR visible bremsstrahlung fibers prior to DT, we made an effort to keep the fiber away from the machine. In our first report on the effects of radiation on fibers ${ }^{14}$, we projected serious problems. As I shall show in the next section, relocation decreased the effect greatly.

\section{Compensation}

When one has moved components away wherever possible, one will still be left with many sensitive items near or even in the tokamak. The bolometers on TFTR must be in the full full plasma radiation fields, for example. The system was therefore designed with blind channels which cannot see the heat radiated by the plasma but are subjected to all the fusion product fluxes. ${ }^{4}$ During a $6 \mathrm{MW}$ DT plasma, the blind channel saw a $5 \%$ fusion heating effect, which was the calculated value for this plasma.

For fiber optics, we must correct for both radioluminescence and transmission loss separately, so we must do something a little more complicated. A good solution is to use a compensation loop.

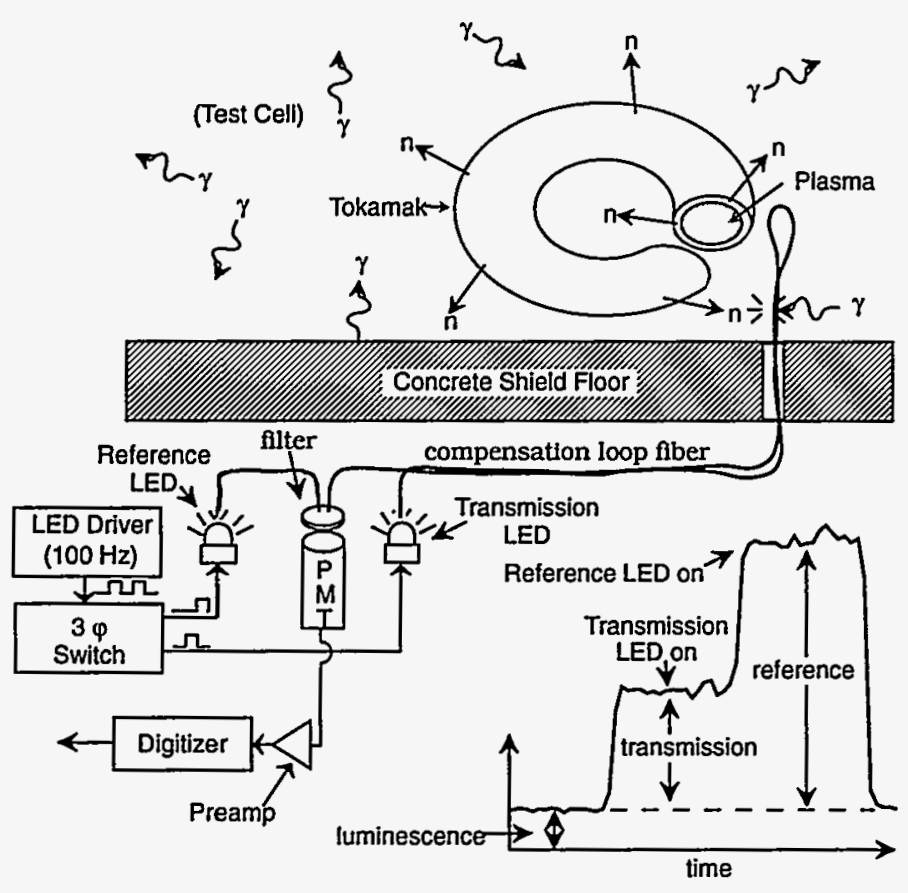

Figure 6. Compensation loop setup. The inset shows a typical trace from the 3-phase fiber excitation scheme used to measure the transmission, luminescence, and detector stability at the same time.
Figure 6 shows the setup of the compensation loops used on TFTR. A loop of fiber runs beside the signal fiber all the way up to the tokamak port cover, then loops back along the same path. The compensation loop is cut from the same fiber reel as the signal fiber. This is important, because different fiber lots, even from the same manufacturer, can have substantially different luminescent yields and transmission loss characteristics. In the data acquisition area, one end of the fiber connects to a light emitting diode (LED) exciter and the other to a photomultiplier detector through a filter at the signal wavelength. Also connected to the detector is a second fiber 
which runs directly to a second, reference LED, driven from the same current source as the transmission LED attached to the source end of the loop. A 3-phase electronic switch goes through a cycle of: both LED's off, transmission LED on, reference LED on. This switch is gated by a $33 \mathrm{~Hz}$ crystal controlled oscillator.

The purpose of the reference LED is to eliminate changes in PMT sensitivity during the shot (there is a varying 100 gauss field at our detector location) and changes in excitation level from sagging or other transients on the power lines. The LED wavelength must be close enough to the signal wavelength to be suitable. ${ }^{15}$ Otherwise, a continuum source (the 18A/T10 tungsten ribbon lamp is an excellent choice) and an interference filter can be used. To chop an incandescent source one needs a rotating wheel, which is a considerable complication, but which allows the reference signal to come from the same source as the transmission signal, thus completing the reference system closed loop. The fiber/detector/filter combination must be absolutely calibrated. We do this using a white card and a transfer standard detector in the same way we calibrate the VB channel itself, ${ }^{16}$ or by cross calibrating from a "closed shutter" shot of the signal channel.

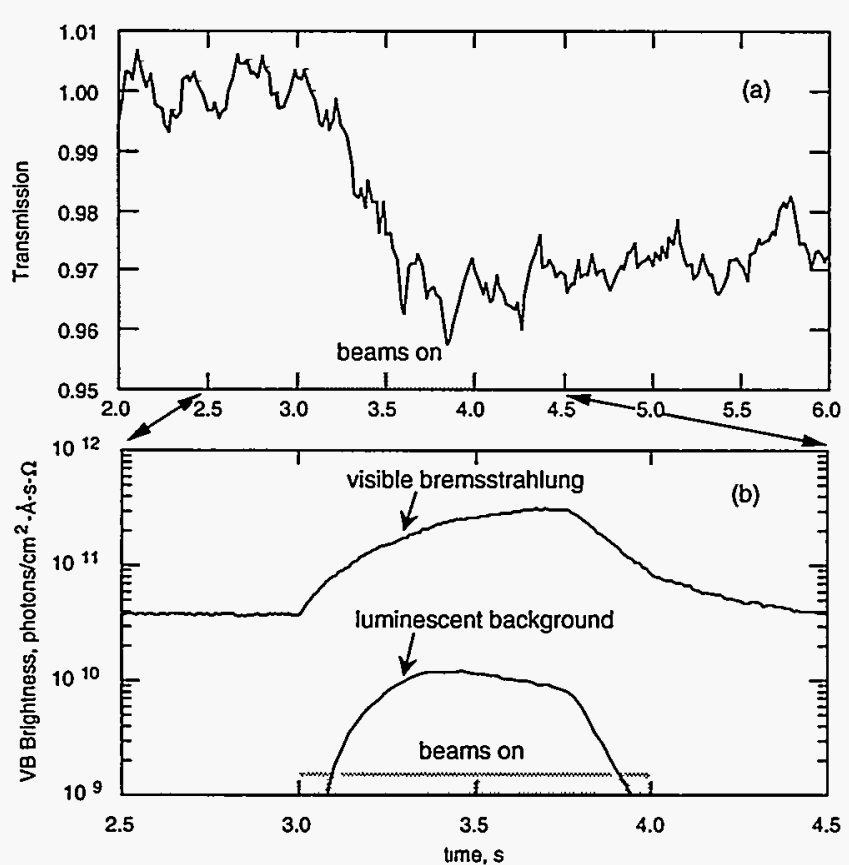

Figure 7. Compensation loop signal for a DT shot producing 6 MW of fusion power. Fig. 7a shows transmission during the beam phase. Fig. $7 \mathrm{~b}$ shows the visible bremsstrahlung signal for this shot with the compensation loop luminescent correction on the same scale. The luminescence follows the neutron rate, and the VB primarily follows the density; hence, the different shapes.
Figure 7 shows how the system works in practice. Fig. 7 a shows the transmission loss during a 6 MW DT plasma, and Fig. 7b shows the luminescence signal compared to the uncorrected VB signal. In an earlier paper, we predicted a large radioluminescent background and transmission loss. ${ }^{14}$ By using better fibers and greatly shortening the fiber length near the machine, we have decreased these contributions by a factor of 10. At $10 \mathrm{MW}$, we will need to take even these effects into account, however, and the compensation loop allows us to do that.

\section{E. Shielding}

When nothing else would suffice, we installed shielding. Both the 
neutron and the gamma fluxes are very high in the TFTR Test Cell, and the shield must stop both. The usual approach is to use a neutron moderator as the outer shield. In addition to a high concentration of protons, the moderator should contain a material with a high thermal neutron cross section. We use polyethylene containing $5 \%$ boron. Inside the moderator we use lead to stop the gammas. For very cramped situations where stacking blocks of moderator and bricks of lead was impractical, we developed a mixture of boron frit and lead shot in an epoxy matrix. (The epoxy serves as a neutron moderator.) This material can be cast into snugly fitting pieces, and while it is not as efficient, inch for inch, as nested neutron moderator and gamma absorber, it works well.

For the TFTR spectrometers, we wanted a shielding factor of 100 in DT, and we calculated that $20 \mathrm{~cm}$ of polyethylene and $10 \mathrm{~cm}$ of lead would give us that. The effect of penetrations must be considered in the design of shielding. Shielding is a complicated but well worked out subject. ${ }^{17}$ It is useful to keep in mind that if you want to achieve a shielding factor of 100 , less than $1 \%$ of the solid angle of the (isotropic) source subtended by the instrument can be open, no matter how thick the shielding material.

For the visible spectrometer VIPS, we achieved a DD shielding factor of 300 in DD and 75 in DT. For the UV survey instrument SPRED we got a DT shielding factor of 72 , also close enough to the design goal.

Figure 8 shows the effects of the shield on SPRED. The first phase of the shielding installation left some apertures at the front of the instrument. (We had been unwilling to load the platform with all the weight necessary to fully block streaming into the

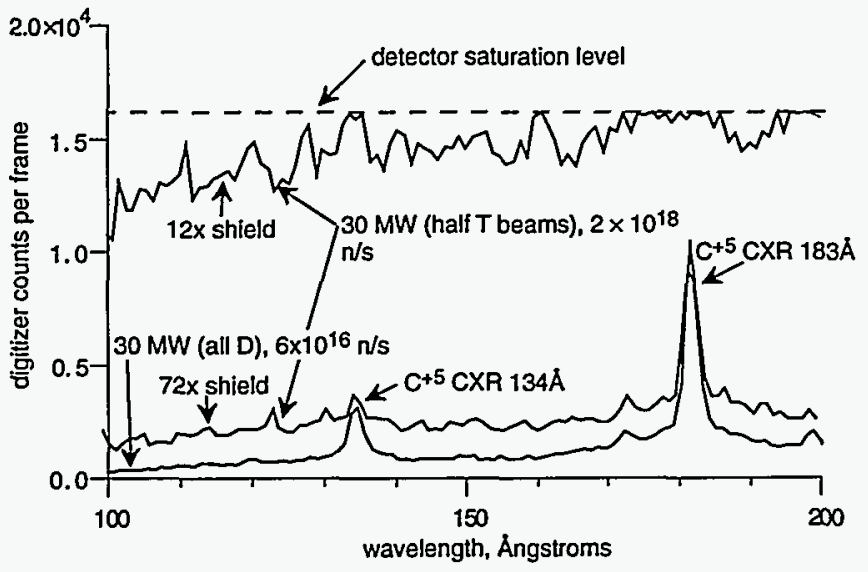

Figure 8. SPRED shielding results, showing the effects of dynamic range loss and noise. The digitizer in the detector saturates at $16 \mathrm{~K}$, and with only a factor of 12 shielding, the signal saturates. When streaming was stopped, we achieved a factor of 72, and recovered a usable signal. front of the instrument.) As the upper trace in the figure shows, we were left with only a shielding factor of 12 , which was insufficient for a modest DT shot. We added $1000 \mathrm{~kg}$ more shielding, and achieved the shielding shown in the middle trace; the effective shielding factor was 72 . This work is described more fully by Hill et al. 18

We conclude that, if carefully applied, normal shielding design is adequate at these radiation levels. On the other hand, the SPRED 
shield weighs $2600 \mathrm{~kg}$, and must be supported on the $2 \mathrm{~m}$ platform that holds SPRED on the tokamak midplane. And the shield adds more than $60 \mathrm{~cm}$ to every diameter of the instrument; a sizable box.

\section{F. Abandonment}

In some cases, we chose to abandon an instrument rather than try to shield it. The vertical charge exchange diagnostic and the extreme grazing incidence spectrometer SOXMOS would have been very difficult to shield. We decided their contributions to DT physics could be foregone. In other cases, we have systems that work well in the DD phase of DT shots, such as the horizontal X-ray crystal spectrometer, and we simply do without the data in DT.

\section{G. Heated fibers}

Finally, I shall describe briefly some of the initial results of a collaborative effort with JET to study the effects of elevated temperatures on radiation susceptibility of silica core optical fibers.

Defects in silica, especially as they effect the use of optical fibers in communications, have been the subject of a large number of papers. A good recent review of this work has been done by Griscom. ${ }^{11}$ Radiation induced defects can be reduced by thermal annealing. This improvement can be the actual elimination of the

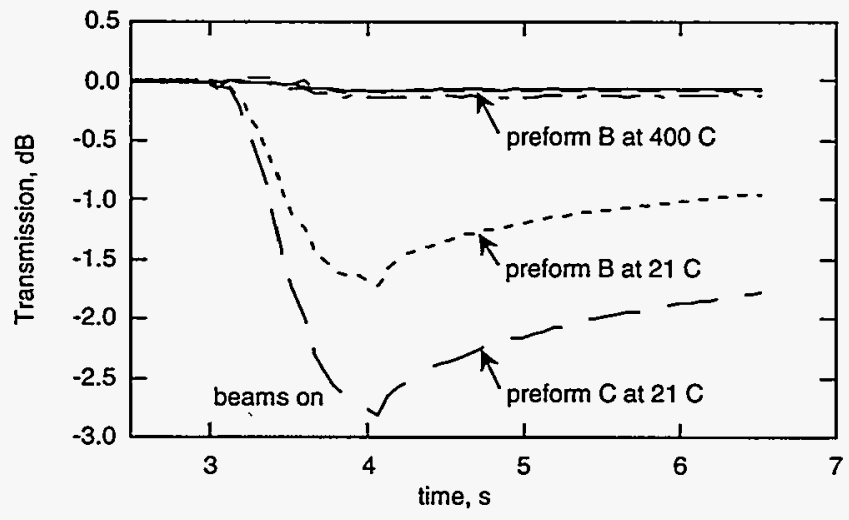

Figure 9. Transmission loss in three $150 \mathrm{~m}$ coils of silica-silica fiber and two sets of shorted fiber leads during a DT plasma on TFTR. The two unheated coils were drawn from different preforms and show different susceptibility. (The preform is the blank of glass from which the fibers are drawn; fibers from the same preform will have the same chemical composition although the drawing process, and thus the defect density, may differ.) The heated coil is from the same preform as the middle curve. When we compare the transmission loss of the heated coil with the shorted connecting lead losses, we conclude that the transmission loss in the heated fiber is consistent with zero. defect, or the thermally assisted removal of the trapped electron in a color center. Both effects increase fiber transmission and reduce that part of the luminescence due to excitation of color centers. Many silica defects anneal at $400 \mathrm{C}$, so we chose that as the temperature to begin testing at.

JET obtained 6 samples of $600 \mu$ core silica-core/silica-clad fiber with a protective jacket of aluminum. The fibers were manufactured by Oxford Electronics (Winchester, U.K.). It is necessary to use silica-silica fiber because polymer cladding cannot survive $400 \mathrm{C}$; similarly, the protective jacket cannot be the 
usual Tefzel or Nylon; hence the aluminum jacket. Silica-silica fibers have a much lower throughput than PCS fibers (with a numerical aperture of 0.20 compared with 0.40 for similar PCS fibers) and are more brittle. They are not widely used.

In Figure 9 we see the first results of this experiment. (A fuller discussion is given by Tighe, et al. ${ }^{19}$ ) Shown are 5 transmission curves, all taken at the same time on the same discharge; the three $155 \mathrm{~m}$ long silica-silica fiber coils were at the same location near the tokamak. The two unheated coils ( $\mathrm{T}=21 \mathrm{C}$ ) show losses of -1.5 and $-3.0 \mathrm{~dB}$ during neutron production, and the beginnings of recovery afterwards. The 3 curves at the top of Fig. 8 are the heated coil and two short-circuited lead loops without silicasilica coils attached. (These leads are $800 \mu$ core PCS fibers used to get the probe light to, and the luminescence and probe signal back from, the silica-silica test coils in the TFTR Test Cell.) The shorted leads are used to correct the coil data for lead effects. The two lead pairs show $-0.06 \mathrm{~dB}$ and $-0.12 \mathrm{~dB}$ loss; the hot fiber coil together with its lead pair shows $-0.08 \mathrm{~dB}$. Thus, the early results are consistent with total elimination of . transmission loss during radiation. On the the hand, there was no reduction in luminescence between $500 \mathrm{~nm}$ and $700 \mathrm{~nm}$, suggesting that in these high purity fibers Cerenkov radiation is the dominating luminescence process. (The silica-silica fibers from Oxford Electronics did not show the enhanced luminescence at $650 \mathrm{~nm}$ shown in Fig. 3.) We are continuing this work.

\section{The future}

TFTR has been able to deal with its DT radiation levels very well. What does the future hold for the other large tokamaks? There are three cases to consider: JET, TPX, and ITER.

\section{A. JET}

JET is scheduled to begin DT operations in 1996. The projected neutron production rate per shot ranges from current TFTR levels ( $6 \mathrm{MW}$ ) for 10 seconds, or 3 times that for 3 seconds. This gives a total neutron production per shot of about 10 times the current TFTR levels.

Like TFTR, JET was designed as a DT facility, and already has many diagnostics distant from the Torus Hall. In addition, the structure around JET is heavier than TFTR, and will absorb much more radiation. Even so, the much larger accumulated dose per shot may cause problems. The heated fiber study we are doing for JET promises to ease some of these concerns. Note that fiber luminescence will be the same to only 3 time higher than TFTR levels even if heating does not help there at all. It is in ameliorating the effects of accumulating opacity in the long JET discharges that heated 
fibers are most promising.

\section{B. TPX}

TPX, the Tokamak Physics Experiment, is a national facility to be built at Princeton University. It is a long pulse (1000 s), superconducting tokamak which will operate with DD plasmas. Because of higher plasma temperatures, TPX will produce a higher DD neutron rate than TFTR, and can continue doing so for 1000 seconds. As a result, the accumulated dose for one day of TPX operation equals a full year of TFTR operation in DD. Along with higher noise levels than we were used to seeing in DD, we have to deal with the buildup of fiber opacity. Not only will the quasi-permanent damage (see the discussion above) accumulate during a shot, the much larger transient opacity will come into secular equilibrium at a level which is not acceptable.

The time behavior of the self-annealing process is complex. (For a more complete

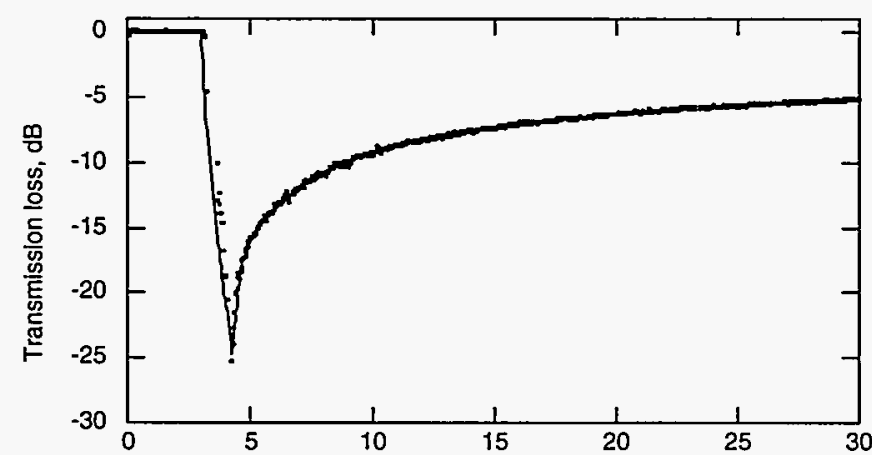

Figure 10. This is a $30 \mathrm{~s}$ history of fiber transmission loss caused by a fluence of $7 \times 10^{12} \mathrm{n}-\mathrm{cm}^{-2}$ (a gamma dose of 200 Rad (Si)). The points are the data, the solid line is a model.

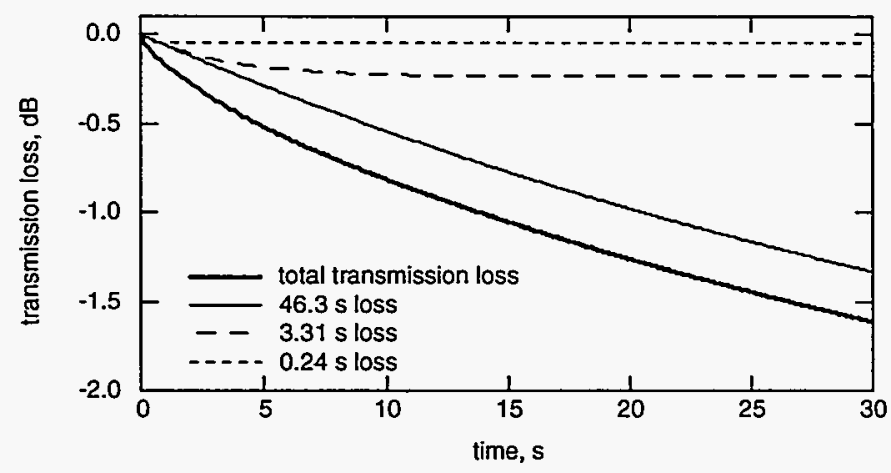

Figure 11. If the same fiber shown in Fig. 10 were made into a typical diagnostic run on TPX, this is the response to 30 seconds of high power operation. The heavy line shows the total transmission loss of the three defect types shown in the model of Fig. 10 discussion see Adler, et al. ${ }^{13}$ ) Here we will take a simple example. In Figure 10, we see the response of one of our fiber study loops to a DT shot, and the first 30 seconds of its recovery. The solid line is a 3 time constant model of defect creation and destruction. We have used this model to predict the response of a typical short run of diagnostic fiber to the DD radiation flux of TPX. (As long as we limit our consideration to time periods over which this model works well, the exact correspondence of the three time constant fit to physical processes in not critical.)

In Fig. 11, we show the transmission of such a fiber for the 30 seconds of the model above. After only 30 seconds, the transmission has fallen an unacceptable $1.5 \mathrm{~dB}(30 \%)$ and is still dropping rapidly.

It is clear from this model that 
either we will have to shield all fibers on TPX or operate them heated. The tradeoffs will have to be considered, and plans to accommodate the added size and complexity of the fiber runs must be made early in the design phase.

\section{ITER}

ITER is a $1000 \mathrm{MW}$ DT machine. The predicted neutron and gamma flux levels at the vacuum vessel are so great that issues of fiber (and window) transmission become irrelevant. Material damage by atomic displacement becomes so serious that the materials won't physically survive. We will be forced to completely rethink the access and interface techniques by which tokamak diagnostics have been done previously. It is likely that optical signals will have to be led out through doglegs and mazes, with front surface reflectors relaying the light. Metal mirrors are among the very few optical devices that can tolerate the $200 \mathrm{~Gy}-\mathrm{s}^{-1}$ dose rates that a plasma facing component receives. Such a relay system can carry the light to a sufficiently low radiation area that a window can be used, and a fiber can then carry the signal to a diagnostic instrument.

It might appear that scanned viewlines and good throughput must be sacrificed in the ITER diagnostic set. This isn't necessarily so. It is possible to design a wide angle scanning system in the visible with a small coupling aperture, $\mathrm{f} / 6$ throughput, and no moving parts near the machine. ${ }^{20}$ And Morsi has installed a fast spectrometer at JET with a dynamically stabilized sightline and no-loss coupling through the JET biological shield. ${ }^{21}$ What probably is true is that optical diagnostics will be forced to operate in the visible and IR, where good uncoated metallic reflectors are available. Bright as ITER will be in the X-ray and UV, getting the signals out unaccompanied by overwhelming radiation streaming will severely tax both our ingenuity and (ultimately) our budget.

\section{Acknowledgements}

Besides those Princeton colleagues whose work I have cited explicitly in this review, I am indebted to J. Bartolick (component failure and electronic design), D. Jassby (neutron production), L. Johnson (neutron detectors), and R. Palladino (shielding and hot fiber'work). P. Morgan (JET) has furnished invaluable support and advice in the heated fiber work. O. N. Jarvis (JET) was helpful in discussions of the JETTFTR radiation spectrum differences. This work was supported by the United States Department of Energy under contract DE-AC02-76-CHO-3073. 


\section{References}

1 D. L. Book. NRL Plasma Formulary (published by Naval Research Laboratory, Washington, DC, 1987).

2 C. W. Barnes, et al., Rev. Sci. Instrum. (to be published) (1994).

3 L. P. Ku and S. L. Liew, in the proceedings of 8 th International Conference on Radiation Shileding, Arlington, Texas, 1994.

4 J. Schivell, et al, Rev. Sci. Instrum. 53, 1527 (1982).

5 K. W. Hill, et al., Rev. Sci. Instrum. 56, 1165 (1985).

6 G. R. McKee, et al., Rev. Sci. Instrum. (to be published) (1994).

7 P. D. Morgan, in the proceedings of Symposium on Fusion Technology, Rome, 1992.

8 O. N. Jarvis, Rev. Sci. Instrum. 63, 4511 (1992).

9 C. E. Bush, R. E. Bell and E. J. Synakowski, Rev. Sci. Instrum (to be published), (1994).

10 D. S. Darrow, Rev. Sci. Instrum. (to be published) (1994).

11 D. L. Griscom, J. Ceram. Soc. Japan 99, 923 (1991).

12 B. L. Pruett, et al, in the proceedings of Fiber Optics in Adverse Environments II, San Diego, 1984. Edited by Greenwall, R.A. SPIE,506, 10.

13 H. G. Adler, et al, Rev. Sci. Instrum. (to be published) (1994).

14 A. T. Ramsey and K. W. Hill, Rev. Sci. Instrum. 63, 4735 (1992).

15 A. T. Ramsey, H. G. Adler and K. W. Hill, Princeton Plasma Physics Lab Report PPPL2867 (1993).

16 A. T. Ramsey and S. L. Turner, Rev. Sci. Instrum. 58, 1211 (1987).

17 N. M. Schaeffer. Reactor Shielding for Nuclear Engineers (National Technical Information Service, Springfield, 1973).

18 K. W. Hill, et al., Rev. Sci. Instrum. (to be published) (1994).

19 W. Tighe, et al. Rev. Sci. Instrum. (to be published) (1994).

20 A. T. Ramsey, Rev. Sci. Instrum. 57, 2017 (1986).

21 H. W. Morsi, et al, in the proceedings of Controlled Fusion and Plasma Physics, Berlin, 1991. Edited by Bachmann, P. \& Robinson, D.C. European Physical Society,IV, 2611 
Dr. F. Paoloni, Univ. of Wollongong, AUSTRALIA

Prof. R.C. Cross, Univ. of Sydney, AUSTRALIA

Plasma Research Lab., Australian Nat. Univ., AUSTRALIA

Prof. I.R. Jones, Flinders Univ, AUSTRALIA

Prof. F. Cap, Inst. for Theoretical Physics, AUSTRIA

Prof. M. Heindler, Institut für Theoretische Physik, AUSTRIA .

Prof. M. Goossens, Astronomisch Instituut, BELGIUM

Ecole Royale Militaire, Lab. de Phy. Plasmas, BELGIUM

Commission-European, DG. XII-Fusion Prog., BELGIUM

Prof. R. Bouciqué, Rijksuniversiteit Gent, BELGIUM

Dr. P.H. Sakanaka, Instituto Fisica, BRAZIL

Prof. Dr. I.C. Nascimento, Instituto Fisica, Sao Paulo, BRAZIL Instituto Nacional De Pesquisas Espaciais-INPE, BRAZIL

Documents Office, Atomic Energy of Canada Ltd., CANADA

Ms. M. Morin, CCFMTTokamak de Varennes, CANADA

Dr. M.P. Bachynski, MPB Technologies, Inc., CANADA

Dr. H.M. Skarsgard, Univ. of Saskatchewan, CANADA

Prof. J. Teichmann, Univ. of Montreal, CANADA

Prof. S.R. Sreenivasan, Univ. of Calgary, CANADA

Prof. T.W. Johnston, INRS-Energie, CANADA

Dr. R. Bolton, Centre canadien de fusion magnétique, CANADA

Dr. C.R. James, Univ. of Alberta, CANADA

Dr. P. Lukác, Komenského Universzita, CZECHO-SLOVAKIA

The Librarian, Culham Laboratory, ENGLAND

Library, R61, Rutherford Appleton Laboratory. ENGLAND

Mrs. S.A. Hutchinson, JET Library, ENGLAND

Dr. S.C. Sharma, Univ. of South Pacific, FIJI ISLANDS

P. Mähönen, Univ. of Helsinki, FINLAND

Prof. M.N. Bussac, Ecole Polytechnique, FRANCE

C. Mouttet, Lab. de Physique des Milieux lonisés, FRANCE

J. Radet, CEN/CADARACHE - Bat 506, FRANCE

Prof. E. Economou, Univ. of Crete, GREECE

Ms. C. Rinni, Univ. of loannina, GREECE

Preprint Library, Hungarian Academy of Sci., HUNGARY

Dr. B. DasGupta, Saha Inst. of Nuclear Physics, INDIA

Dr. P. Kaw, Inst. for Plasma Research, INDIA

Dr. P. Rosenau, Israel Inst. of Technology, ISRAEL

Librarian, International Center for Theo Physics, ITALY

Miss C. De Palo, Associazione EURATOM-ENEA , ITALY

Dr. G. Grosso, Istituto di Fisica del Plasma, ITALY

Prof. G. Rostangni, Istituto Gas lonizzati Del Cnr, ITALY
Dr. H. Yamato, Toshiba Res \& Devel Center, JAPAN

Prof. I. Kawakami, Hiroshima Univ., JAPAN

Prof. K. Nishikawa, Hiroshima Univ., JAPAN

Librarian, Naka Fusion Research Establishment, JAERI, JAPAN

Director, Japan Atomic Energy Research Inst., JAPAN

Prof. S. Itoh, Kyushu Univ., JAPAN

Research Info. Ctr., National Instit. for Fusion Scienc, JAPAN

Prof. S. Tanaka, Kyoto Univ., JAPAN

Library, Kyoto Univ., JAPAN

Prof. N. Inoue, Univ. of Tokyo, JAPAN

Secretary, Plasma Section, Electrotechnical Lab., JAPAN

Dr. O. Mitarai, Kumamoto Inst. of Technology, JAPAN

Dr. G.S. Lee, Korea Basic Sci. Ctr., KOREA

J. Hyeon-Sook, Korea Atomic Energy Research Inst., KOREA

D.I. Choi, The Korea Adv. Inst. of Sci. \& Tech., KOREA

Prof. B.S. Liley, Univ. of Waikato, NEW ZEALAND

Inst of Physics, Chinese Acad Sci PEOPLE'S REP. OF CHINA Library, Inst. of Plasma Physics, PEOPLE'S REP. OF CHINA Tsinghua Univ. Library, PEOPLE'S REPUBLIC OF CHINA Z. Li, S.W. Inst Physics, PEOPLE'S REPUBLIC OF CHINA Prof. J.A.C. Cabral, Instituto Superior Tecnico, PORTUGAL Prof. M.A. Hellberg, Univ. of Natal, S. AFRICA

Prof. D.E. Kim, Pohang Inst. of Sci. \& Tech., SO. KOREA

Prof. C.I.E.M.A.T, Fusion Division Library, SPAIN

Dr. L. Stenflo, Univ. of UMEA, SWEDEN

Library, Royal Inst. of Technology, SWEDEN

Prof. $H$. Wilhelmson, Chalmers Univ. of Tech., SWEDEN Centre Phys. Des Plasmas, Ecole Polytech, SWITZERLAND Bibliotheek, Inst. Voor Plasma-Fysica, THE NETHERLANDS Asst. Prof. Dr. S. Cakir, Middle East Tech. Univ., TURKEY Dr. V.A. Glukhikh,Sci. Res. Inst. Electrophys.l Apparatus, USSR Dr. D.D. Ryutov, Siberian Branch of Academy of Sci., USSR Dr. G.A. Eliseev, I.V. Kurchatov Inst., USSR Librarian, The Ukr.SSR Academy of Sciences, USSR Dr. L.M. Kovrizhnykh, Inst. of General Physics, USSR Kemforschungsanlage GmbH, Zentralbibliothek, W. GERMANY Bibliothek, Inst. Für Plasmaforschung, W. GERMANY Prof. K. Schindler, Ruhr-Universitát Bochum, W. GERMANY Dr. F. Wagner, (ASDEX), Max-Planck-Institut, W. GERMANY Librarian, Max-Planck-Institut, W. GERMANY 